\title{
Templates for Quantifying Clay Type and Clay Content from Magnetic Susceptibility and Standard Borehole Geophysical Measurements
}

\author{
David K. Potter ${ }^{1}$, Arfan Ali², Salem Abdalah ${ }^{3}$ \\ ${ }^{1}$ Department of Physics, University of Alberta, Edmonton, Canada \\ ${ }^{2}$ Brunei Shell Petroleum, Sendirian Berhad, Brunei Darussalam \\ ${ }^{3}$ Institute of Petroleum Engineering, Heriot-Watt University, Edinburgh, UK \\ Email: *dkpotter@ualberta.ca
}

How to cite this paper: Potter, D.K., Ali, A. and Abdalah, S. (2019) Templates for Quantifying Clay Type and Clay Content from Magnetic Susceptibility and Standard Borehole Geophysical Measurements. Journal of Modern Physics, 10, 824-834. https://doi.org/10.4236/jmp.2019.107055

Received: May 13, 2019

Accepted: June 21, 2019

Published: June 24, 2019

Copyright (c) 2019 by author(s) and Scientific Research Publishing Inc. This work is licensed under the Creative Commons Attribution International License (CC BY 4.0).

http://creativecommons.org/licenses/by/4.0/

\begin{abstract}
This paper proposes a rapid means of identifying clay type and quantifying clay content from new template crossplots that compare magnetic susceptibility measurements with standard borehole well log data. The templates are similar in format to standard industry charts, but have a number of advantages over the commonly used charts. Laboratory measurements of magnetic susceptibility on core samples and drill cuttings have recently shown strong correlations with key petrophysical parameters, particularly clay content and fluid permeability [1] [2]. A new template crossplot between magnetic susceptibility and borehole spectral gamma ray log data can firstly help to quickly identify the types of clay present in the formation. Additional new template crossplots between magnetic susceptibility and borehole bulk density data allow the mineral contents and porosities of binary mixtures of clay minerals and matrix minerals (such as illite clay + quartz) to be rapidly quantified. The templates can use ambient (room temperature) magnetic susceptibility data from measurements on core samples or drill cuttings in the laboratory or at the wellsite. Furthermore, the paper shows how the templates can potentially be extended to utilize borehole magnetic susceptibility data for in situ estimations of the type and content of clay. This requires accounting for the temperature dependence of the magnetic susceptibility of paramagnetic minerals (such as illite clay), which varies with depth in a borehole. Whilst borehole magnetic susceptibility measurements are rarely part of standard well logging operations, they could be a potentially useful tool for in situ clay type and content quantification, which in turn can help predict fluid permeability.
\end{abstract}

\section{Keywords}

Magnetic Susceptibility, Clay, Spectral Gamma Ray, Bulk Density, Borehole 
Logs, Temperature Dependence, Core, Drill Cuttings

\section{Introduction}

Standard industry charts for identifying mineralogy, such as the widely used Schlumberger well logging interpretation charts [3], concentrate on the bulk matrix minerals quartz $\left(\mathrm{SiO}_{2}\right)$ for clastic reservoirs, and calcite $\left(\mathrm{CaCO}_{3}\right)$ and dolomite $\left(\mathrm{CaMg}\left(\mathrm{CO}_{3}\right)_{2}\right)$ for carbonate reservoirs. Small amounts of other minerals are important components of reservoir rocks, and can have key controls on the petrophysical properties. In particular, the type and content of certain clay minerals (such as fibrous illite) can significantly control the fluid permeability of the rock (i.e., the ability of fluids to flow through the rock). There is little in terms of reference charts for identifying clay minerals, apart from some standard charts using borehole data from spectral gamma ray (e.g., potassium versus thorium crossplot [3]) or using the spectral gamma ray log data in combination with photoelectric log (PEF) data [3]. Whilst a combination of the thorium/potassium ratio and PEF log data can identify clay mineral type within relatively narrow ranges, none of these standard charts can give a quantitative estimate of the clay content.

The purpose of the present paper is to show how the new template crossplots, utilizing magnetic susceptibility measurements in combination with certain standard borehole log data, can rapidly quantify the clay content in addition to identifying the clay type. It has been demonstrated that magnetic susceptibility measurements on core samples [1] and more recently on drill cuttings [2] provide a rapid, non-destructive tool for estimating clay content and relating this to fluid permeability, and other special core analysis (SCAL) parameters such as the cation exchange capacity per unit pore volume, $\mathrm{Q}_{\mathrm{v}}[1]$. We now present some new template crossplots, similar in format to standard industry crossplot charts [3], which utilize magnetic susceptibility and some standard wire line log data (specifically spectral gamma ray and bulk density), as a new tool for rapidly estimating clay type and content. The new crossplots use magnetic susceptibility measurements at ambient temperature undertaken in the laboratory on core samples (core plugs, slabbed core or whole core), or at the wellsite on drill cuttings, to estimate clay type and content. Paramagnetic clays in particular, such as illite, can be a major control on fluid permeability and other petrophysical parameters [1]. The clay content derived from the new template crossplots can subsequently help to rapidly estimate fluid permeability, since strong correlations between magnetically derived illite content and fluid permeability have been demonstrated in core samples [1] and drill cuttings [2], and other petrophysical parameters (such as $\mathrm{Q}_{\mathrm{v}}$ ), via this "quick look" analysis well before the actual core permeability and other data become available. Whilst there are other methods of determining clay type and content, such as by X-ray diffraction (XRD), these methods can be time consuming, expensive and semi-quantitative. 
We envisage our proposed template crossplots as a rapid complement to these other techniques, rather than as a replacement.

We also describe how the templates can potentially be extended to utilize borehole magnetic susceptibility data, in combination with other borehole data, to estimate clay type and content in situ. This involves incorporating the temperature dependence on magnetic susceptibility of paramagnetic minerals, and extends our earlier work in this area [4]. Whilst borehole magnetic susceptibility devices are rarely used at present in standard well logging tool strings, our new template crossplots indicate the potential usefulness of running such tools to estimate clay type and content in situ straight from the well logging data.

\section{Methodologies and New Templates}

\subsection{Determining Clay Type from a Template Utilizing Magnetic Susceptibility and Standard Borehole Spectral Gamma Ray Data}

The first step is to identify the clay type. A rapid new potential way of doing this is to plot borehole spectral gamma ray data against magnetic susceptibility from core samples or drill cuttings. Figure 1 shows a new plot of thorium/potassium $(\mathrm{Th} / \mathrm{K})$ ratio from borehole spectral gamma ray data against mass magnetic susceptibility (at ambient temperature) for mixtures of quartz plus different clay minerals. The $\mathrm{Th} / \mathrm{K}$ data originates from sources such as [5] and has been utilized in standard industry charts [3], whilst the magnetic susceptibility data comes from four main sources [6] [7] [8] [9]. The mass magnetic susceptibility is $J / H$ where $J$ is the magnetization per unit mass and $H$ is the applied field strength.

Figure 1 would be applicable for laboratory or wellsite magnetic susceptibility measurements on core samples or drill cuttings at ambient (room temperature) conditions $\left(20^{\circ} \mathrm{C}\right.$ in our case). Each rectangle represents the range of values from $100 \%$ quartz to $100 \%$ of the relevant mineral indicated. Each rectangle starts at a mass magnetic susceptibility value of $-0.619 \times 10^{-8} \mathrm{~m}^{3} \mathrm{~kg}^{-1}$ (100\% quartz [9]). Most of the clay minerals shown are paramagnetic (with positive magnetic susceptibility), and as the percentage of each mineral increases the mass magnetic susceptibility increases. For these minerals the top of each rectangle represents $100 \%$ of the mineral indicated in the rectangle. For example, the $100 \%$ quartz to $100 \%$ biotite range is from $-0.619 \times 10^{-8} \mathrm{~m}^{3} \mathrm{~kg}^{-1}$ to $98 \times 10^{-8} \mathrm{~m}^{3} \mathrm{~kg}^{-1}$. The only exception to this in Figure 1 is kaolinite, which is diamagnetic with low negative magnetic susceptibility [7] [9], and the bottom of that rectangle represents $100 \%$ kaolinite. The different types of clay occupy fairly well defined regions of Figure 1. There is a small degree of overlap between the $\mathrm{Th} / \mathrm{K}$ ratios of illite and muscovite, which is difficult to show on the figure, and the muscovite and biotite magnetic susceptibility values overlap in the region $-0.619 \times 10^{-8} \mathrm{~m}^{3} \mathrm{~kg}^{-1}$ to $15 \times$ $10^{-8} \mathrm{~m}^{3} \mathrm{~kg}^{-1}$.

The applicability of Figure 1 can be extended to utilize borehole magnetic susceptibility data for in situ clay typing. For diamagnetic clay minerals, such as 


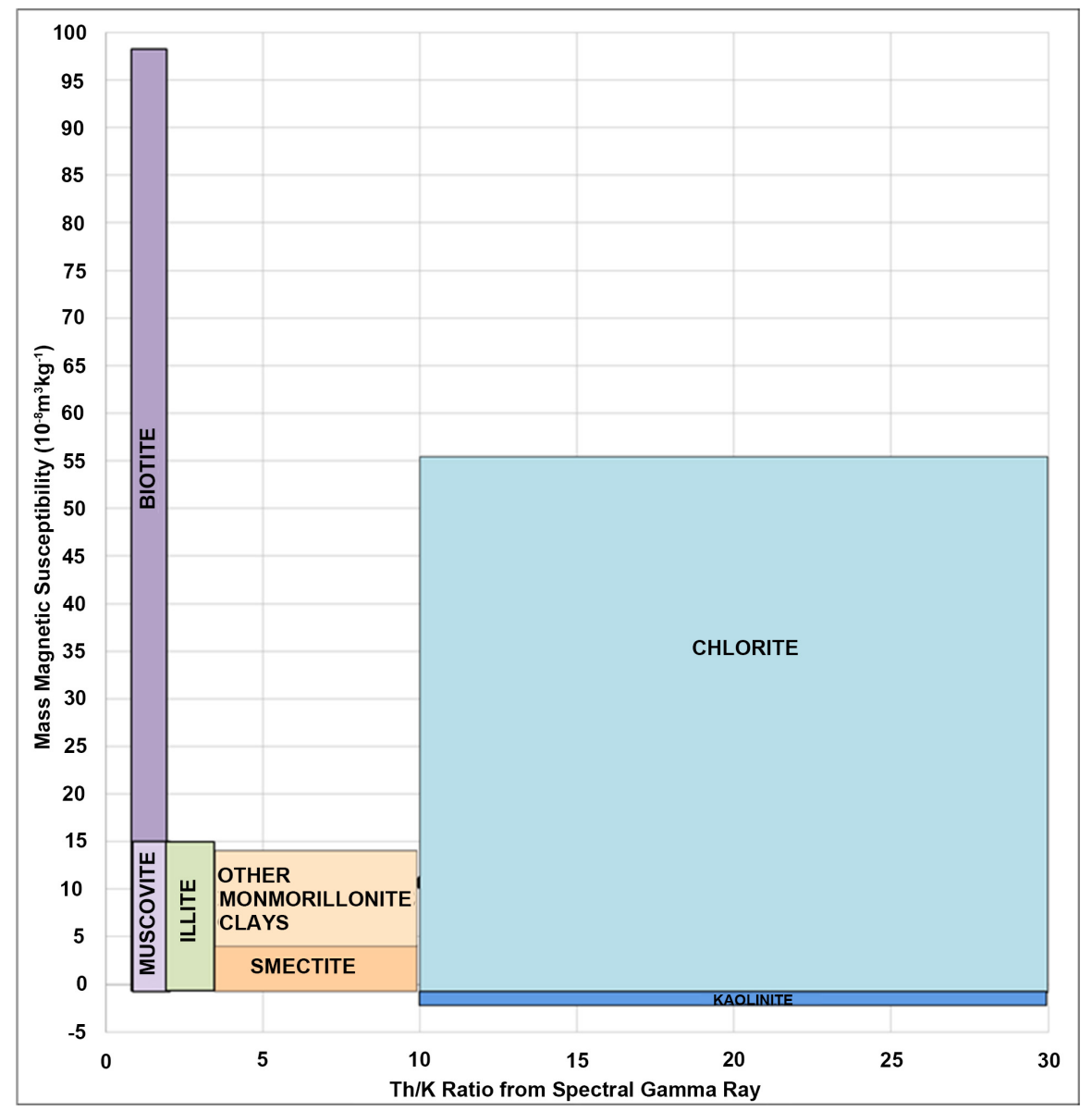

Figure 1. Spectral gamma ray thorium/potassium $(\mathrm{Th} / \mathrm{K})$ ratio [5], where $\mathrm{Th}$ is in parts per million and $\mathrm{K}$ is in per cent, versus mass magnetic susceptibility (at ambient temperature) for mixtures of quartz plus different minerals as indicated. Each rectangle starts at $-0.619 \times 10^{-8} \mathrm{~m}^{3} \mathrm{~kg}^{-1}(100 \%$ quartz [9]) on the mass magnetic susceptibility axis, and the rectangles represent the range of values from $100 \%$ quartz to $100 \%$ of the mineral indicated based on magnetic susceptibility values for those minerals [6] [7] [8] [9]. Note that increasing kaolinite content results in more negative magnetic susceptibility, since kaolinite is diamagnetic [7] [9].

kaolinite, the magnetic susceptibility values for borehole measurements will be identical to those in Figure 1, since the magnetic susceptibility of diamagnetic minerals is not dependent on temperature. However, for the paramagnetic clay minerals shown (i.e., illite, chlorite, montmorillonite, smectite, biotite, muscovite) the maximum magnetic susceptibility values shown in Figure 1 will decrease with increasing temperature according to the Curie Law as follows:

$$
J / H=C / T
$$

where $J$ is the magnetization per unit mass, $H$ is the strength of the applied magnetic field ( $H=B / \mu_{0}$, where $B$ is the applied field in Tesla and $\mu_{0}$ is the magnetic permeability of free space), $J / H$ is the mass magnetic susceptibility, $C$ is a mineral specific Curie constant, and $T$ is the absolute temperature in Kelvin. Equation (1) can also be expressed in terms of volume magnetic susceptibility, 
$M / H$, where $M$ is the magnetization per unit volume. Temperature normally increases with depth. If one knows the temperature at any particular depth (most well logging operations include a temperature log), or one knows the depth and the local geothermal gradient (i.e., the variation of temperature with depth at that locality), then the magnetic susceptibility can be calculated. An example of the variation of magnetic susceptibility with temperature for different mixtures of illite clay + quartz is given in our earlier work [4].

Determining clay type from Figure 1 has a number of advantages as follows:

1) The ranges of the different minerals are much smaller than for charts that use spectral gamma ray data alone, such as standard potassium (in percentage) versus thorium (in parts per million) plots [3].

2) Whilst some standard charts that are derived entirely from borehole data (such as $\mathrm{Th} / \mathrm{K}$ ratio from the spectral gamma ray log versus PEF from the lithodensity $\log$ ) also have relatively narrow ranges for the clay minerals, the clay type from Figure 1 can be obtained via rapid, non-destructive magnetic susceptibility measurements on core samples or drill cuttings without the need to run a PEF log. Furthermore, the use of drill cuttings could be extremely cost effective (compared to core samples which are expensive to obtain) since these are readily available in every drilled well. One might also use portable spectral gamma ray equipment on core or drill cuttings, without the need to run a spectral gamma ray log. Often just the total gamma ray log is run, which is cheaper than running a full spectral gamma ray log.

3) Magnetic susceptibility measurements on core and drill cuttings are much quicker and cheaper than other laboratory techniques for determining clay type and content, such as X-ray diffraction (XRD) [1] [10]. However, if supplementary mineralogical data is available (from XRD, thin sections etc.) then this will help to confirm the binary mineral mixture for the quantification of clay described in Section 2.2 below.

4) Whilst Figure 1 details binary mixtures of quartz + clay minerals, the figure would be virtually identical (and indistinguishable on the current vertical $y$-axis scale) if we plotted calcite + clay minerals or dolomite + clay minerals. This is because quartz, calcite and dolomite are all diamagnetic with very similar low, negative magnetic susceptibilities $\left(-0.619 \times 10^{-8} \mathrm{~m}^{3} \mathrm{~kg}^{-1},-0.484 \times 10^{-8} \mathrm{~m}^{3} \mathrm{~kg}^{-1}\right.$ and $-0.480 \times 10^{-8} \mathrm{~m}^{3} \mathrm{~kg}^{-1}$ respectively [9]). The advantage of this is that Figure 1 can be used to identify clay type in clastic (quartz matrix) reservoirs or carbonate (calcite and /or dolomite) reservoirs.

There are, however, some limitations of our proposed clay typing methodology:

1) The method assumes a binary mixture of a matrix mineral (such as quartz or calcite) with a clay mineral. If there is a mixture of more than one clay mineral the point plotted on Figure 1 will represent the combined effect of all those minerals in the sample, which may make it difficult to identify the individual clay minerals present. Nevertheless, this is also a limitation of the current stan- 
dard industry charts based on spectral gamma ray data [3]. Moreover, whilst reservoir rocks can contain several mineral components, there are often two key components that dominate. For example, binary mixtures of quartz + illite are commonly the dominant mineral components in certain conventional reservoirs [1] and unconventional (e.g., shale) reservoirs [11] [12] [13].

2) In some reservoir rocks small amounts of ferrimagnetic minerals (e.g., magnetite, $\mathrm{Fe}_{3} \mathrm{O}_{4}$ ) can dominate a low field magnetic susceptibility signal, and obscure the signal from the clays. Any ferrimagnetic minerals in the sample will result in a higher magnetic susceptibility value on Figure 1 compared to the value from the clay minerals alone. However, this is generally not an issue if one undertakes a high field magnetic susceptibility measurement. At high applied fields (more than about $300 \mathrm{mT}$ ) magnetite saturates and no longer contributes to the magnetic susceptibility signal, leaving just the signal from the paramagnetic clays (or other paramagnetic minerals) and the diamagnetic minerals like quartz or calcite [9] [14]. Note that hematite $\left(\alpha-\mathrm{Fe}_{2} \mathrm{O}_{3}\right)$ is a rare exception that may need even higher fields to saturate. High field magnetic susceptibility measurements require more specialist equipment than low field measurements, however low field measurements are often sufficient for the present purposes.

\subsection{Template Crossplots for Quantifying Clay Content from Magnetic Susceptibility and Standard Borehole Bulk Density Data}

The second step in the procedure is to quantify the amount of clay. Figure 2 shows an example template crossplot of mass magnetic susceptibility (at ambient temperature) versus bulk density for various mixtures of illite clay and quartz, which can be used for quantifying illite (and quartz) by plotting magnetic susceptibility measurements on core samples or drill cuttings in the laboratory or at the wellsite in conjunction with the borehole bulk density data (or core derived bulk density). Figure 2 assumes a simple mixture of the two components, with the mass magnetic susceptibilities of the end members being $15 \times 10^{-8} \mathrm{~m}^{3} \mathrm{~kg}^{-1}$ for $100 \%$ illite [8] and $-0.619 \times 10^{-8} \mathrm{~m}^{3} \mathrm{~kg}^{-1}$ for $100 \%$ quartz [9]. The bulk densities were taken as $2.75 \mathrm{~g} / \mathrm{cm}^{3}$ for illite (an average of values given in [15]) and $2.65 \mathrm{~g} / \mathrm{cm}^{3}$ for quartz [3].

Figure 2 also takes account of realistic formation rock porosities ranging from $0 \%$ to $40 \%$, and so can also be used as a rapid way to estimate the porosity of the binary mineral mixture. Figure 2 assumes water filled porosity, as is standard practice for other widely used industry charts [3]. The magnetic susceptibility values will not change significantly if the porosity is filled with water, oil or gas as in most cases these fluids are diamagnetic with quite similar low negative magnetic susceptibilities [16].

Figure 2 has a significant advantage over another commonly used standard industry chart, which uses neutron porosity versus bulk density to estimate porosity and mineralogy of the matrix minerals quartz, calcite and dolomite [3]. If 


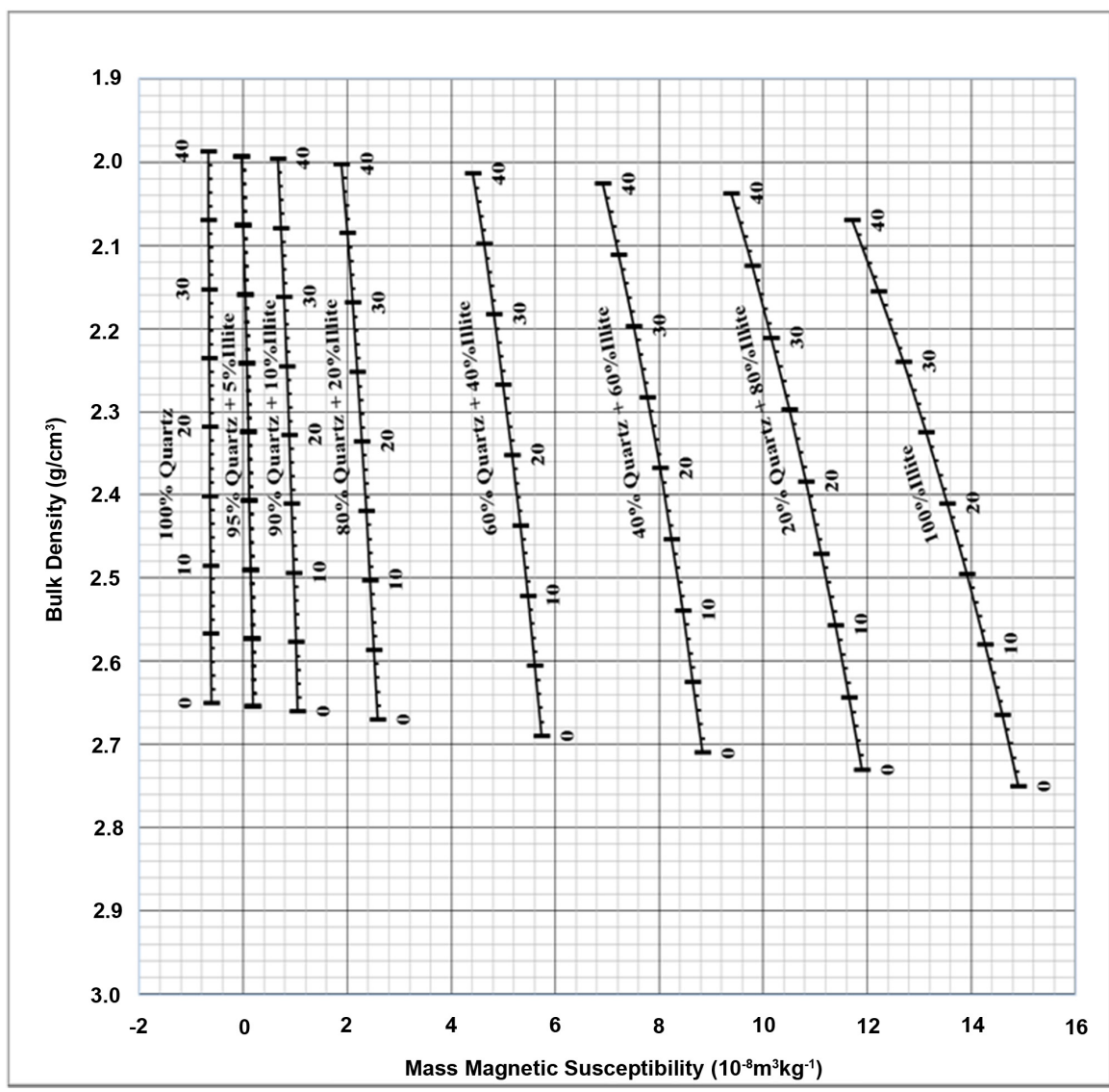

Figure 2. Template crossplot of mass magnetic susceptibility (at ambient temperature) versus bulk density for mixtures of quartz and illite as indicated. The numbers $0,10,20$, 30 and 40 represent the percentage porosity of the mixture (i.e., $0 \%$ to $40 \%$ ).

there is any clay in the sample the "apparent" neutron porosity increases due to bound water in the clay, and does not reflect the real (lower) porosity of the sample. The neutron tool sees all of the hydrogen in the sample, and it can't distinguish hydrogen in bound water in clay from hydrogen in fluid (i.e., liquid water, hydrocarbons) filled porosity. Our Figure 2, in contrast, utilizes magnetic susceptibility rather than neutron porosity, and the porosities derived from our magnetic susceptibility versus bulk density values will not be adversely affected by the clay present in the samples, and will better reflect the actual porosities of the samples.

Figure 3 is a similar plot to Figure 2, but gives a template for much lower illite contents. Very low percentages of illite clay can have a dramatic effect on a sample's fluid permeability [1], and so it is useful to have a template that is capable of quantifying very small percentages of illite.

\subsection{Extending the Templates for Quantifying Clay Content in Situ from Borehole Magnetic Susceptibility Measurements Combined with Borehole Bulk Density Data}

As discussed in Section 2.1 the magnetic susceptibility of a paramagnetic mineral such as illite clay decreases with increasing temperature (and therefore also 


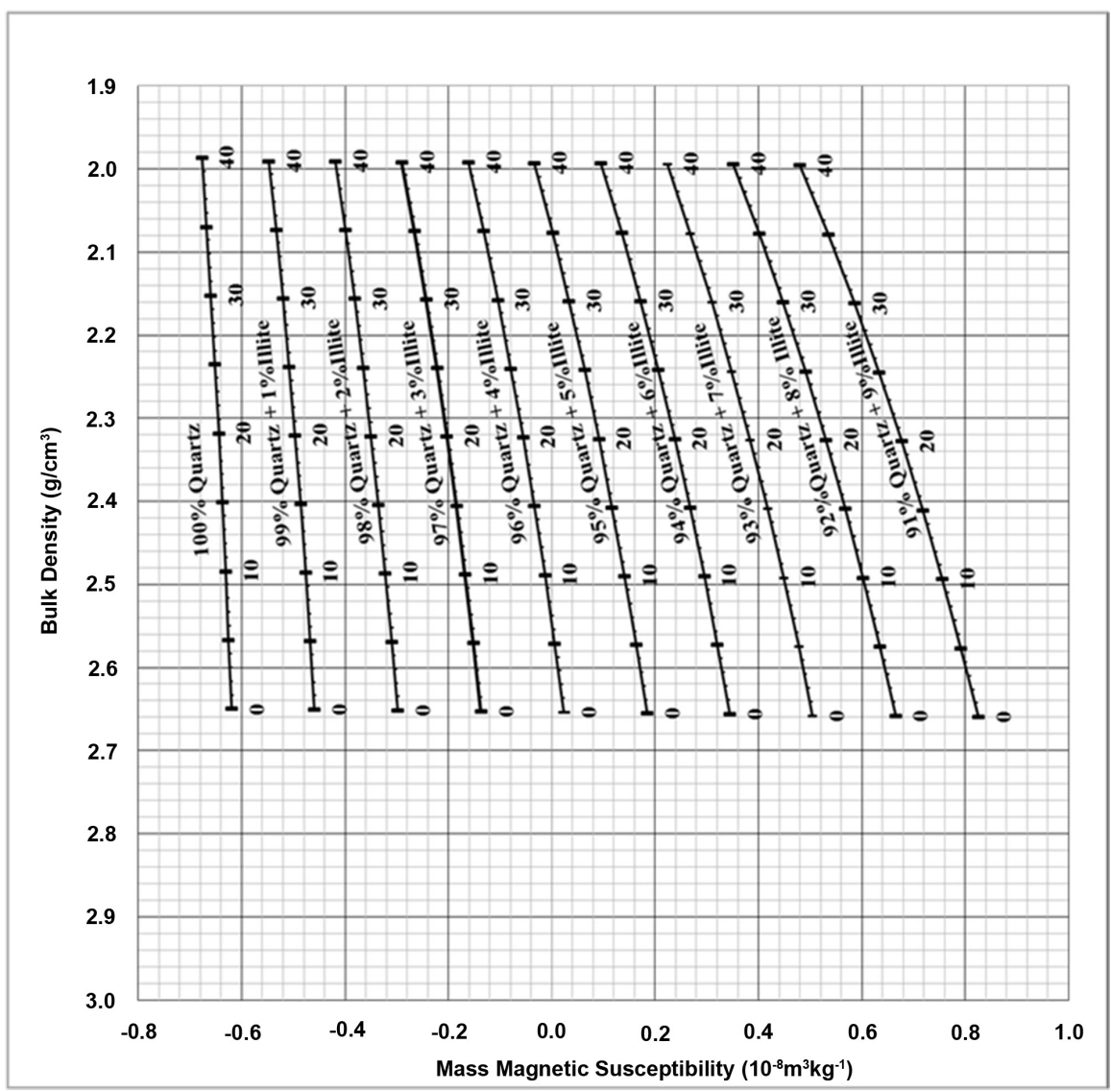

Figure 3. Template crossplot of mass magnetic susceptibility (at ambient temperature) versus bulk density for further mixtures of quartz and illite where the illite content is low $(0 \%-10 \%)$. The numbers $0,10,20,30$ and 40 represent the percentage porosity of the mixture (i.e., $0 \%$ to $40 \%$ ).

generally with depth) according to the Curie Law (Equation (1)). Therefore similar plots to Figure 2 and Figure 3 at different temperatures could be used to quantify illite content from in situ borehole magnetic susceptibility and bulk density data. The binary mineral mixture lines would merely be shifted by varying amounts to the left (i.e., to lower magnetic susceptibilities), dependent upon the temperature, for any temperature above ambient (room temperature) used for Figure 2 and Figure 3. However, that would require many plots similar to Figure 2 and Figure 3, each at a different temperature. A better and simpler approach to quantify clay content from in situ borehole measurements would be to just use the borehole magnetic susceptibility data alone (without the bulk density data). The clay content could be quantified from a single magnetic susceptibility versus temperature plot for several different percentage mixtures of a particular binary mineral combination. An example of such a plot for illite + quartz mixtures is given by us in [4].

Alternatively, if the bulk density data were to be included, then the temperature dependence of the magnetic susceptibility could be shown on 3D plots. Figure 4 shows one such example of a 3D plot of mass magnetic susceptibility 


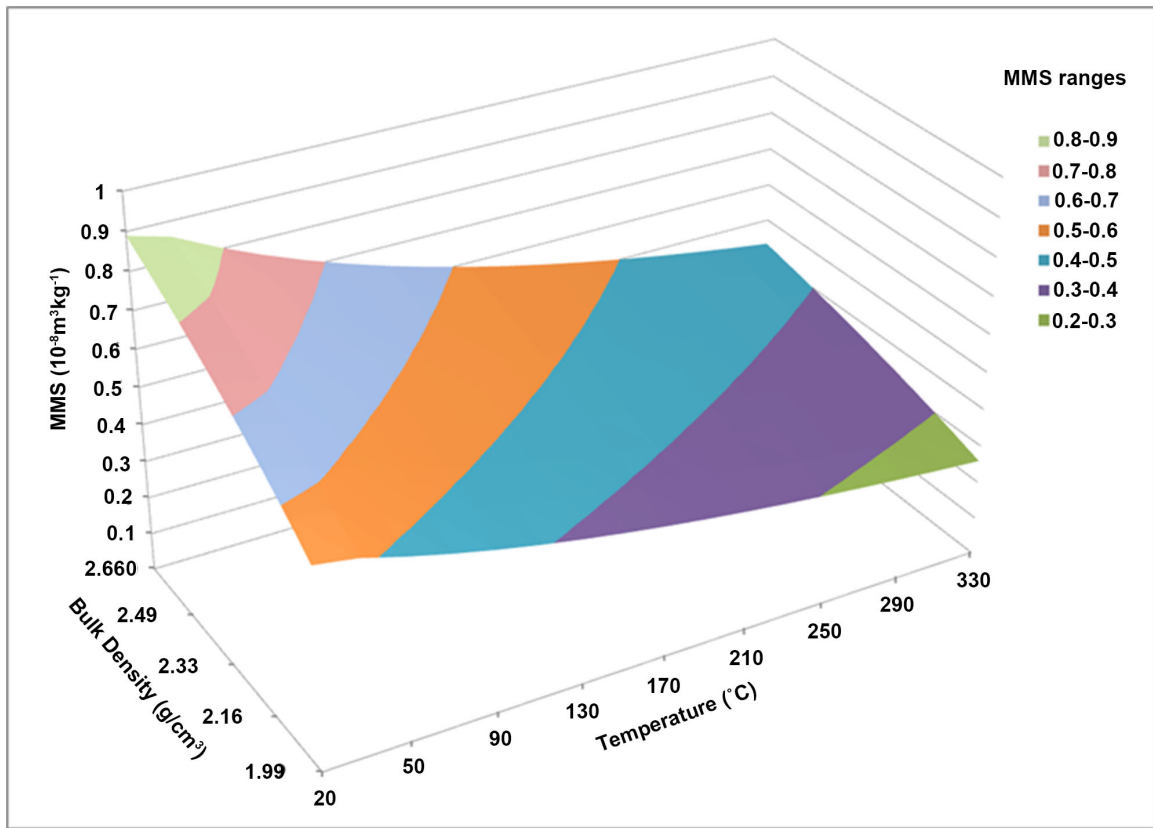

Figure 4. 3D plot of mass magnetic susceptibility (MMS) versus bulk density as a function of temperature for a mixture of $9.5 \%$ illite and $90.5 \%$ quartz. The MMS ranges in the legend have units of $10^{-8} \mathrm{~m}^{3} \mathrm{~kg}^{-1}$.

versus bulk density as a function of temperature for a binary mixture comprising 9.5\% illite and $90.5 \%$ quartz. The decrease in mass magnetic susceptibility with increasing temperature is clearly shown. For mixtures with a higher illite content than those shown in Figure 4 the magnetic susceptibility values at any temperature would be higher (likewise mixtures with a lower illite content will have lower magnetic susceptibility values), and would decrease with increasing temperature according to Equation (1). 3D plots like Figure 4 have the advantage of being able to include an additional parameter (in this case bulk density), but the disadvantage in that a separate plot is required for each binary mineral mixture.

\section{Conclusions}

A methodology to rapidly and non-destructively identify clay type and quantify clay content is proposed, which utilizes some new template crossplots of magnetic susceptibility versus standard borehole data (or core data) involving spectral gamma ray and bulk density. The binary mineral mixture (e.g., illite clay + quartz) can first be identified from Figure 1, and then the individual mineral contents of the binary mixture, together with the mixture porosity, can be quantified from plots like Figure 2 and Figure 3. The new plots have a number of advantages over other more traditional plots and techniques as we detailed.

The new plots can utilize magnetic susceptibility measurements at ambient temperatures in the laboratory or at the wellsite using core samples or drill cuttings. The use of drill cuttings would be particularly cost effective, since these are produced for any drilled well at essentially no extra cost (unlike expensive core 
samples).

The methodology can also utilize borehole magnetic susceptibility measurements to identify the clay type (in conjunction with spectral gamma ray data), and quantify the clay content, in situ using the borehole magnetic susceptibility data alone or in combination with borehole bulk density data. For these in situ applications from borehole measurements, the plots need to take account of the temperature dependence of the magnetic susceptibility of paramagnetic minerals, since reservoir temperatures vary with depth in boreholes.

\section{Acknowledgements}

D. K. P. thanks the Natural Sciences and Engineering Research Council of Canada (NSERC) for a Discovery Grant.

\section{Conflicts of Interest}

The authors declare no conflicts of interest regarding the publication of this paper.

\section{References}

[1] Potter, D.K. (2007) Petrophysics, 48, 191-201.

[2] Banks, J.Y., Tugwell, A.G. and Potter, D.K. (2018) Constraining Uncertainty in Complex Reservoir Description-A Case History Applying Magnetic Susceptibility to Estimate Permeability from Core Samples and Cuttings. 59th Annual Logging Symposium, London, 2-6 June 2018, 11 p.

[3] Log Interpretation Charts (2005) Schlumberger. 279.

[4] Ali, A. and Potter, D.K. (2012) Geophysics, 77, WA211-WA221. https://doi.org/10.1190/geo2011-0282.1

[5] Fertl, W.H. (1979) The Log Analyst, 20, 3-37.

[6] Borradaile, G.J., MacKenzie, A. and Jensen, E. (1990) Journal of Geophysical Research (Solid Earth), 95, 8447-8451. https://doi.org/10.1029/JB095iB06p08447

[7] Dearing, J.A. (1994) Environmental Magnetic Susceptibility: Using the Bartington MS2 System. Chi Publishing, Kenilworth.

[8] Hunt, C.P., Moskowitz, B.M. and Banerjee, S.K. (1995) Magnetic Properties of Rocks and Minerals. In: Ahrens, T.J., Ed., Rock Physics and Phase Relations: $A$ Handbook of Physical Constants, AGU Reference Shelf Vol. 3, American Geophysical Union, Washington DC, 189-204. https://doi.org/10.1029/RF003p0189

[9] Potter, D.K., AlGhamdi, T.M. and Ivakhnenko, O.P. (2011) Petrophysics, 52, 50-57.

[10] Potter, D.K., Corbett, P.W.M., Barclay, S.A. and Haszeldine, R.S. (2004) Journal of Sedimentary Research, Research Methods Papers Section, 74, 730-735. https://doi.org/10.1306/021304740730

[11] Ross, D.J.K. and Bustin, R.M. (2008) AAPG Bulletin, 92, 87-125. https://doi.org/10.1306/09040707048

[12] Dehghanpour, H., Zubair, H.A., Chhabra, A. and Ullah, A. (2012) Energy Fuels, 26, 5750-5758. https://doi.org/10.1021/ef3009794

[13] Makhanov, K.K. (2013) An Experimental Study of Spontaneous Imbibition in Horn River Shales. MSc Thesis, University of Alberta, Edmonton, 109. 
https://doi.org/10.2118/162650-MS

[14] Potter, D.K. and Ivakhnenko, O.P. (2008) Petrophysics, 49, 57-66.

[15] Deer, W.A., Howie, R.A. and Zussman, J. (1983) An Introduction to the Rock Forming Minerals. Longman Group Limited, London, 528.

[16] Ivakhnenko, O.P. and Potter, D.K. (2004) Physics and Chemistry of the Earth, 29, 899-907. https://doi.org/10.1016/j.pce.2004.06.001 